\title{
Post-drug consequences of chronic atypical antipsychotic drug administration on the ability to adjust behavior based on feedback in young monkeys
}

\author{
Dorothy J. Mandell • Alan Unis • Gene P. Sackett
}

Received: 24 August 2010 / Accepted: 9 December 2010/Published online: 8 January 2011

(C) The Author(s) 2011. This article is published with open access at Springerlink.com

\begin{abstract}
Rationale Atypical antipsychotic drugs are characterized by their affinity for serotonin and dopamine receptors. The dopaminergic system undergoes developmental changes during childhood, making it vulnerable to external influences such as drug administration.

Objective The purpose of this study was to assess the longterm effects of administering risperidone and quetiapine to 12-24-month-old macaque monkeys on cognitive development, a maturational equivalent to 4-8-year-old children.

Methods Forty male pigtailed macaques were used in the study ( $n=20$ placebo, $n=10$ risperidone, $n=10$ quetiapine). Following a 4-month pre-drug period, animals were orally administered $2 \mathrm{mg} / \mathrm{kg}$ of quetiapine and $.025 \mathrm{mg} / \mathrm{kg}$ of risperidone daily for 4 months, then the dosage was doubled for another 4 months. They were followed up for 4 months after cessation
\end{abstract}

D. J. Mandell ( $\bowtie)$

Department of Psychology, Developmental Psychology,

University of Amsterdam,

Roetersstraat 15,

1018 WB Amsterdam, The Netherlands

e-mail: d.j.mandell@uva.nl

A. Unis

College of Pharmacy and Therapeutics,

Washington State University,

Pullman, WA, USA

A. Unis

Kootenai Medical Center,

Coeur d'Alene, ID, USA

G. P. Sackett

Infant Primate Research Laboratory, Washington National Primate

Research Center \& Center on Human Development and

Disability, University of Washington,

Seattle, WA, USA of the drug. Animals were assessed through all phases of the study on two-object discrimination and learning set.

Results Cognitive development was not negatively affected while the animals were being administered the drug. However, the risperidone group had significant decrements in performance on the learning set task after cessation of the drug $(p=$ 0.006, $\eta_{\mathrm{p}}{ }^{2}=0.59$ ). Analysis of errors showed that the risperidone group had a significant increase in perseverative responding during the post-drug phase $\left(p=0.002, \eta_{\mathrm{p}}{ }^{2}=0.67\right)$. Conclusion As with human studies, neither risperidone nor quetiapine had a negative impact on cognitive development during the drug phases. However, the results show that the risperidone group had behavioral impairment post-drug, suggesting that the drug may have impacted the development of the dopaminergic system.

Keywords Atypical drugs · Risperidone - Quetiapine · Development $\cdot$ Cognition $\cdot$ Children $\cdot$ Pediatric

\section{Introduction}

Atypical antipsychotic drugs, called second-generation antipsychotics (SGAs), have been shown to be effective in controlling aggressive and externalizing behaviors, as well as bipolar disorder in pediatric populations (Bishop and Pavuluri 2008; Pandina et al. 2007, 2009). All SGAs target the thalamic-striatal-frontal loop, which has been shown to be important in several cognitive functions such as rewardbased learning (Schultz 2002), cognitive flexibility (Cools 2006), and working memory (Kellendonk et al. 2006). The striatal and frontal dopaminergic (DA) systems interact directly and indirectly through serotonin (5HT) type 2 receptors, which are selectively targeted by SGAs (Schotte et al. 1996). The 5HT2/D2 affinity ratio of the drug in the striatium is related to the degree that prefrontal dopamine 
increases (Kuroki et al. 1999) and the clinical efficacy of the drug (Kuroki et al. 1999; Meltzer and McGurk 1999).

The 5HT system matures early in development. However, the DA system has protracted postnatal developmental trajectories that are divergent for receptor sub-types and different areas (Lambe et al. 2000; Tarazi and Baldessarini 2000). Within the striatum, neurotransmitter synthesis and turnover change between early and late childhood (Haycock et al. 2003). The developmental trajectory of D2 receptors in the striatum appears to lag behind these changes, peaking in late childhood then declining into puberty (Andersen and Teicher 2000; Tarazi and Baldessarini 2000). Within the frontal cortex, receptor concentrations of D1, D2, and D4 increase from late childhood and into early adolescence, then concentrations decline to adult levels (Tarazi and Baldessarini 2000; Wahlstrom et al. 2009). These changes, coupled with the finding that SGAs affect the immature striatal DA system differently than the mature system (Moran-Gates et al. 2007), suggest that these drugs could have long-term effects on cognitive development.

In children, SGAs have been associated with modest improvements in recognition memory and attention, but these effects are not large or consistent (Aman et al. 2008; Gunther et al. 2006; Pandina et al. 2009). One consistent finding from these studies is that SGAs do not impair cognition while the child is taking the drug. However, a major difficulty when judging the cognitive effect in these studies is that they often include patient groups with large variations in IQ and do not assess IQ by drug interaction. These variations in general cognition could be contributing to the discrepancy in the findings. Additionally, these studies did not follow up the child after the drug was discontinued, leaving open the question about how these drugs interact with the developing DA system.

The main purpose of this study was to assess the effect of chronic quetiapine or risperidone administration on the ability to adjust behavior based on feedback. We focused on this domain because it is well established in nonhuman primates that DA neurons in the thalamic-striatal-frontal loop are involved (Tremblay et al. 1998). Additionally, there are parallel developmental improvements in this domain through the early juvenile period between humans (Levinson and Reese 1967; Reese 1989) and nonhuman primates (Harlow et al. 1960; Mandell and Sackett 2009). The extended juvenile period in nonhuman primates in comparison to rats, as well as the established parallels in cognitive development between nonhuman primates and humans makes this research especially suited for a monkey model. These drugs were chosen because both are being actively prescribed to children as young as 4 years old (Chang 2008; Kowatch et al. 2005). Additionally, the receptor affinity profiles make them interesting to compare in order to disentangle any effects due to 5HT or DA antagonism. Risperidone has high affinity for 5HT2 and D2 receptors giving it a moderate 5HT2/D2 affinity ratio (Schotte et al. 1996). Quetiapine, however, has very low affinity for D2 receptors, giving it one of the highest 5HT2/ D2 affinity ratios in this class of drug (Schotte et al. 1996). Given the affinity profiles of the drugs, it was expected that both quetiapine and risperidone would have modest effects on cognitive development during administration, but only risperidone would have long-term effects after the drug was discontinued.

\section{Experimental procedures}

\section{Subjects and rearing condition}

All procedures were approved by the University of Washington Institutional Animal Care and Use Committee. Forty male pigtail macaques (Macaca nemestrina) were used in the study. All animals were mother-reared in 0.10 ha outdoor corrals at the Tulane National Primate Research Center, Covington, Louisiana. Between 6 and 7 months of age, juveniles were shipped to the Washington National Primate Center, Infant Primate Laboratory (IPRL) in Seattle.

Animals arrived at the IPRL in cohorts of five, all within 30 days of age of each other. They were kept in accordance with standard husbandry protocols for feeding, cage cleaning, and health assessments. Although individually housed with visual and auditory access to other monkeys, all had 30-45 min of daily playgroup socialization with their cohort throughout the study.

At 12 months, each cohort was reduced to four animals in order to balance the drug and placebo monkeys in the social group. The dropped animal either exhibited abnormal development or health problems $(n=3)$ or was randomly chosen $(n=7)$. The remaining four animals in the cohort were randomly assigned to a drug group so that each cohort consisted of two placebo animals and two receiving a drug. This resulted in a sample of 40 animals: 20 received a placebo, 10 received quetiapine, and 10 received risperidone. Animals within a cohort were assigned to the same drug. All laboratory staff were blind to the experimental assignment of the animals.

\section{Dosing schedule}

Animals were first adapted to the laboratory setting for 4 6 weeks. During this time, they were trained to drink butterscotch syrup out of a syringe. After this initial adaptation period, animals began a 07:00-hour dosing regime that occurred 7 days a week (Table 1). During the pre-drug phase that occurred from 9 to 12 months, all animals were administered the butterscotch placebo at $1 \mathrm{ml} / \mathrm{kg}$ of liquid. 
concentrations $(\mathrm{ng} / \mathrm{ml})$ over the study period presented by phase was taken. Standard deviations are in parentheses. These data are published in Sackett et al. (2010)

${ }^{\text {a }}$ Values significantly different from the placebo group at each measurement
Table 1 Prolactin and month in phase the measure

\begin{tabular}{|c|c|c|c|c|c|c|}
\hline & \multirow{2}{*}{$\begin{array}{l}\text { Pre-drug } \\
\text { Month } 3\end{array}$} & \multicolumn{2}{|l|}{ Low-dose } & \multicolumn{2}{|c|}{ Moderate-dose } & \multirow{2}{*}{$\begin{array}{l}\text { Post-drug } \\
\text { Month } 1\end{array}$} \\
\hline & & Month 1 & Month 3 & Month 1 & Month 3 & \\
\hline \multirow[t]{2}{*}{ Placebo } & 10.2 & 10.1 & 9.9 & 10.1 & 9.7 & 9.1 \\
\hline & $(5.9)$ & $(6.2)$ & $(6.7)$ & (6.3) & (7.4) & (5.8) \\
\hline \multirow[t]{2}{*}{ Risperidone } & 12.5 & $42.0^{\mathrm{a}}$ & $20.8^{\mathrm{a}}$ & $32.2^{\mathrm{a}}$ & $25.5^{\mathrm{a}}$ & $8.7^{\mathrm{a}}$ \\
\hline & $(4.9)$ & $(16.6)$ & (8.8) & $(14.2)$ & $(7.6)$ & (4.3) \\
\hline \multirow[t]{2}{*}{ Quetiapine } & 12.5 & 10.3 & 6.6 & 6.4 & 9.4 & 9.7 \\
\hline & (7.6) & $(6.3)$ & $(2.5)$ & $(2.2)$ & $(4.5)$ & $(4.1)$ \\
\hline
\end{tabular}

Low-dose phase: At 13 months, animals assigned to a drug group were given either $2 \mathrm{mg} / \mathrm{kg}$ of quetiapine or $.025 \mathrm{mg} / \mathrm{kg}$ of risperidone. The drug and placebo were suspended in the butterscotch solution so that all animals were receiving $1 \mathrm{ml} / \mathrm{kg}$ of syrup. The dose was adjusted for each animal once a week based on his average weight gain the previous week. Moderate-dose phase: At 17 months, the dosage was doubled to $4 \mathrm{mg} / \mathrm{kg}$ of quetiapine and $.05 \mathrm{mg} / \mathrm{kg}$ of risperidone. Postdrug phase: At 21 months, all animals were switched back to placebo for 2 weeks after which time dosing was discontinued. The moderate dose corresponds to a $1.2-\mathrm{mg} /$ day dose of risperidone and a $120-\mathrm{mg} / \mathrm{day}$ dose of quetiapine for a 30-kg child. Both dose levels are low for children but have been shown to be clinically effective in pediatric patients (Bishop and Pavuluri 2008; Roke et al. 2009).

\section{Medical and health assessments}

Each animal's weight was assessed daily and growth measures were taken at the end of each month. Blood draws were taken without sedation at the end of the first and third month of each phase. Blood was assayed for prolactin and thyroxin at the University of Washington Department of Laboratory Medicine as part of a blood chemistry panel. Prolactin concentrations and growth for each group are reported elsewhere (Sackett et al. 2010). Prolactin results are shown in Table 2. It is important to note that neither the risperidone nor the quetiapine group showed abnormal weight gain in comparison to the placebo animals over the course of the study.

\section{Cognitive testing}

Animals began cognitive testing during the pre-drug phase (Table 1). Cognitive testing was conducted 5 days per week in a Wisconsin General Testing Apparatus, which has been described extensively (Mandell and Sackett 2009). Animals within a cohort were tested at least $3 \mathrm{~h}$ but no more than $8 \mathrm{~h}$ after their morning dose. Animals were tested on a battery of six cognitive tasks (http://depts.washington.edu/iprl/ iprl testing.html). Each of these tasks was administered at developmentally appropriate ages; therefore, not all tasks were administered equally across the drug phases. The tasks not reported here will be presented in subsequent reports.

In each drug phase, animals were tested on two-object discrimination. The animal was presented with a black and a white plastic block, each placed over a well, with one well containing a small piece of fruit. Either the black or white block, counterbalanced in the cohort, signaled the location of the reward on all trials. The location of the reward was pseudorandomly determined on each trial so that the same location was not rewarded more than three trials in a row. In the pre-drug phase, the animal was tested until it was correct on $90 \%$ of the trials in a 24 -trial session. In the predrug phase only, the reward association was also reversed. For the purpose of this study, only the data from the initial
Table 2 Dosing and cognitive testing schedule with age in days and standard deviations in parentheses

\begin{tabular}{|c|c|c|c|c|}
\hline Age & $\begin{array}{l}\text { Pre-drug phase } \\
264.2(17.3)\end{array}$ & $\begin{array}{l}\text { Low-dose phase } \\
379.8(16.6)\end{array}$ & $\begin{array}{l}\text { Moderate-dose phase } \\
491.8 \text { (16.6) }\end{array}$ & $\begin{array}{l}\text { Post-drug phase } \\
603.9(16.8)\end{array}$ \\
\hline \multicolumn{5}{|c|}{ Two-object discrimination } \\
\hline Placebo & $279.2(20.5)$ & $390.2(31.7)$ & $499.6(26.9)$ & $618.9(38.0)$ \\
\hline Risperidone & $271.4(12.9)$ & 395.7 (33.9) & $488.8(14.4)$ & $621.7(38.8)$ \\
\hline Quetiapine & $289.6(27.8)$ & $392.8(17.7)$ & $525.8(37.2)$ & $616.8(17.7)$ \\
\hline \multicolumn{5}{|l|}{ Learning set } \\
\hline Placebo & $367.9(17.0)$ & $452.6(24.6)$ & $558.5(24.7)$ & $621.4(29.1)$ \\
\hline Risperidone & $358.5(12.9)$ & $446.8(15.9)$ & $535.1(32.7)$ & $628.2(37.0)$ \\
\hline Quetiapine & $371.8(16.2)$ & $456.1(31.0)$ & $577.2(24.2)$ & $624.9(18.1)$ \\
\hline
\end{tabular}


discrimination was included in the analyses. The reward association formed during reversal in the pre-drug phase was maintained through the remaining three phases of the study. In these phases, the task was administered 1 day a week for 8 weeks in the two drug phases and for 4 weeks in the post-drug phase, regardless of performance.

The animal was also tested on learning set formation. Animals were presented with two unique "junk" objects, such as old toys and small objects. The objects were presented using the same procedure as in two-object discrimination. An object pair was presented for six trials, and then a new pair was presented. Six object pairs were presented in each test session. An animal performing this task is typically $50 \%$ correct on the first trial but becomes better on trials 2 thru 6 as it learns to use the outcome of trial 1 to guide subsequent behavior. Animals were initially tested on 240 object pairs that began in the pre-drug phase and extended into the beginning of the low-dose phase. At the end of the low-dose phase and in each subsequent phase, animals were tested on 30 object pairs. In order to compare performance across all phases, only the last 30 pairs administered in each of the phases were analyzed.

\section{Results}

Unless otherwise noted, analyses were conducted with repeated-measures analysis of variance. The GreenhouseGeisser correction was used when assumptions of sphericity were not met and corrected $p$ values are reported. For each analysis, drug phase was a within-subjects variable and drug group was a between-subjects variable. Planned contrasts were also conducted comparing post-drug performance to high- and low-drug phase performance.

Animals improved on two-object discrimination as the study progressed in terms of overall proportion correct $(F$ $\left.(3,111)=45.03, p<0.001, \eta_{\mathrm{p}}{ }^{2}=0.54\right)$. Performance did not significantly interact with drug group, indicating that animals in each group were able to learn and maintain the association comparably across all phases of the study. The group means during each phase for this task are shown in Table 3.

Learning set performance showed a different pattern. There was a significant phase by drug group interaction $(F$ $\left.(6,108)=2.88, p=0.019, \eta_{\mathrm{p}}{ }^{2}=0.14\right)$. Planned comparisons showed that the source of this group difference was between the moderate- and post-drug phases $(F(2,36)=$ 6.91, $\left.p=0.003, \eta_{\mathrm{p}}{ }^{2}=0.28\right)$. Performance by the risperidone group was negatively affected by cessation of the drug. Their post-drug performance was significantly worse than their moderate-dose performance $(F(1,9)=12.81, p=.006$, $\eta_{\mathrm{p}}{ }^{2}=0.59$ ). This performance pattern is in contrast with the placebo group whose best performance was in the post-drug
Table 3 Performance expressed as proportion correct on two-object discrimination across the four drug phases. Standard deviations are in parentheses

\begin{tabular}{lcccc}
\hline & $\begin{array}{l}\text { Pre-drug } \\
\text { phase }\end{array}$ & $\begin{array}{l}\text { Low-dose } \\
\text { phase }\end{array}$ & $\begin{array}{l}\text { Moderate- } \\
\text { dose phase }\end{array}$ & $\begin{array}{l}\text { Post-drug } \\
\text { phase }\end{array}$ \\
\hline Placebo & 0.72 & 0.94 & 0.94 & 0.93 \\
& $(0.10)$ & $(0.14)$ & $(0.08)$ & $(0.12)$ \\
Risperidone & 0.77 & 0.89 & 0.93 & 0.94 \\
& $(0.12)$ & $(0.15)$ & $(0.13)$ & $(0.12)$ \\
Quetiapine & 0.68 & 0.97 & 0.97 & 0.99 \\
& $(0.15)$ & $(0.04)$ & $(0.02)$ & $(0.01)$ \\
\hline
\end{tabular}

phase (low-dose vs. post-drug: $p=0.007, \eta_{\mathrm{p}}{ }^{2}=0.34$; moderate-dose vs. post-drug: $p=0.07, \eta_{\mathrm{p}}{ }^{2}=0.17$ ) and the quetiapine group whose performed at a high level throughout testing. These relationships are shown in Fig. 1.

In order to determine the source of the performance decline on learning set, reaction time and response strategies were analyzed. Reaction times between the groups were comparable and typical for this task. Animals were significantly slower on trial 1 than on any other trial $\left(\eta_{\mathrm{p}}{ }^{2}=0.76\right)$, this pattern did not significantly interact with drug group and was maintained into the post-drug phase.

To assess whether the risperidone group engaged in specific or random errors, performance on the first and second trials of each object pair was analyzed (Harlow 1949). This grouping resulted in four mutually exclusive and exhaustive response strategies: (1) correct-correct, (2) incorrect-correct, (3) incorrect-incorrect, and (4) correctincorrect. The most adaptive of these strategies are the first two, the "win-stay, lose-shift" strategies. The third strategy is a perseverative strategy and indicates a lack of ability to use trial 1 information to adjust trial 2 behavior. The fourth strategy is rare in this species of macaque and indicates random responding.

Figure 2 shows the utilization rates of the lose-lose and the lose-win strategies for each group across all four drug phases. For the optimal lose-win strategy, there was a nonsignificant interaction between performance on the moderate- and post-drug phases and drug group. In the post-drug phase, the risperidone group's utilization of this strategy was not significantly lower than the placebo group but it was significantly lower than the quetiapine group ( $t$ $(36)=2.11, p=0.04)$. For the lose-lose perseverative strategy, there was a significant drug group by phase interaction $\left(F(6,105)=2.84, p=0.019, \eta_{\mathrm{p}}{ }^{2}=0.14\right)$. This interaction was driven by performance differences between the moderateand post-drug phases $\left(F(2,35)=7.56, p=0.002, \eta_{\mathrm{p}}{ }^{2}=0\right.$. $30)$. The risperidone group showed a significant increase in this suboptimal strategy. Their rate of utilization for this strategy in the post-drug phase was higher than at any time 

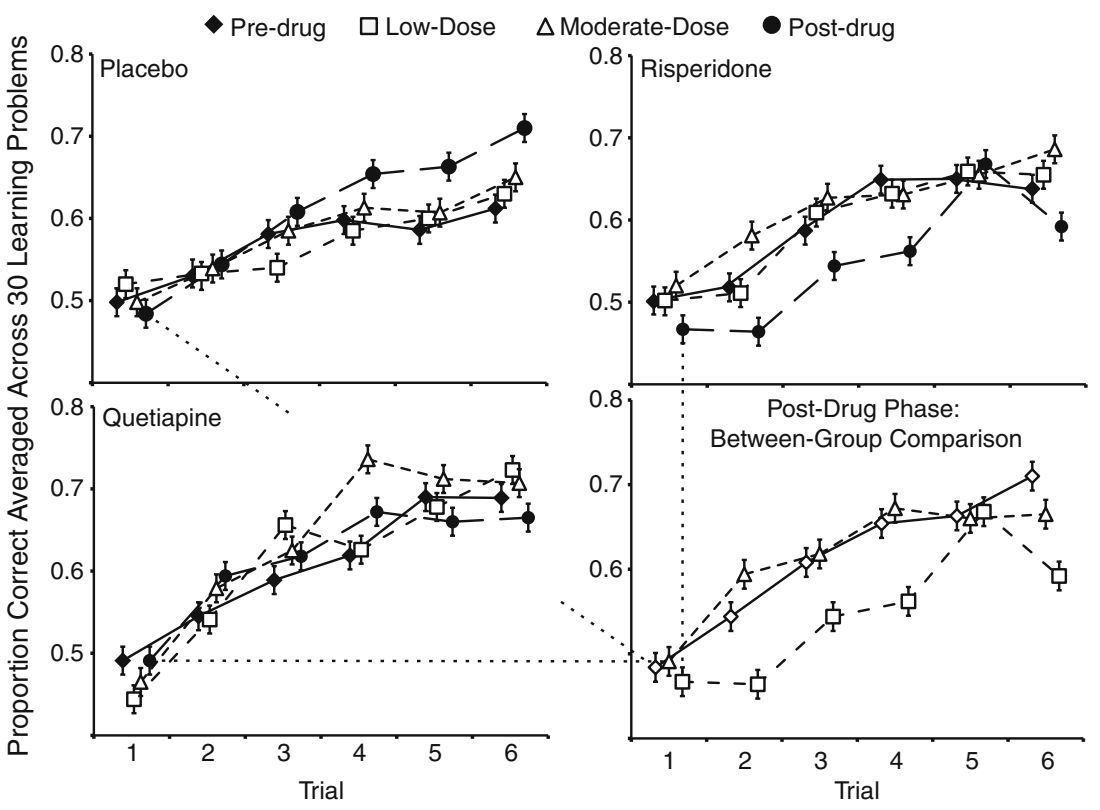

Fig. 1 Learning set performance for each of the drug groups across the four phases of the study. Points for each trial are artificially gapped to avoid overlapping of error bars. Error bars represent \pm 1 S.E. Performance across the last 30 object pairs presented in each phase was averaged, resulting in a learning curve across six trials. The initial pre-drug assessment was conducted at 11 months of age. The last 30

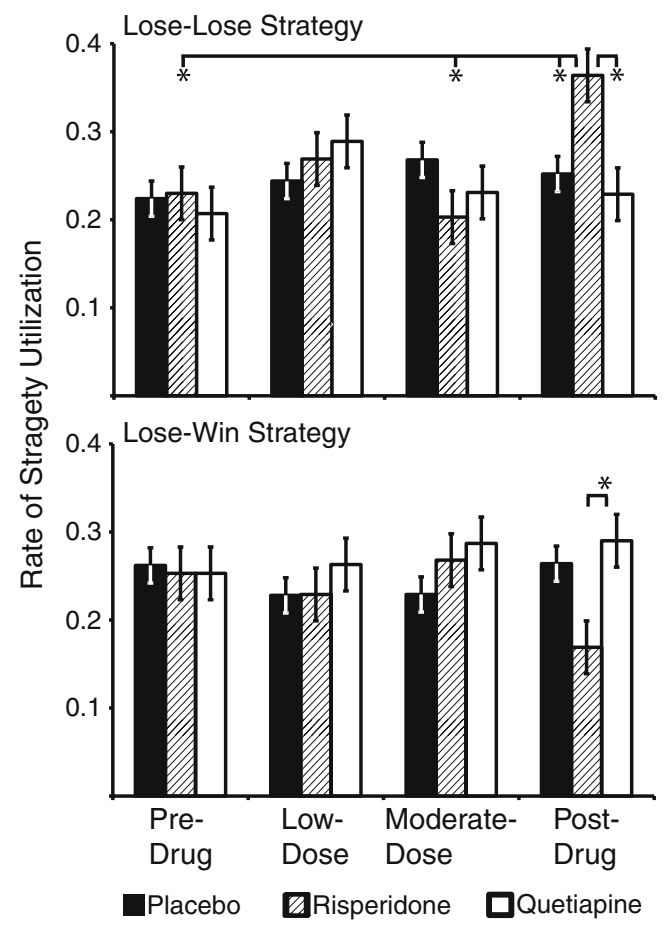

trials of the assessment were conducted at 15 months of age in the low-dose phase. The moderate-dose phase assessment was conducted at 18 months. The post-drug phase assessment was conducted at 22 months, 20-30 days after cessation of the drug. Data from the postdrug phase are shown in the last panel to highlight the between-group differences during this phase

in the study (pre- and post-drug: $p=.006, \eta_{\mathrm{p}}{ }^{2}=0.59$, lowand post-drug: $p=0.07, \eta_{\mathrm{p}}{ }^{2}=0.31$, moderate- and post-drug: $\left.p=0.002, \eta_{\mathrm{p}}{ }^{2}=0.67\right)$. Additionally, they utilized this strategy significantly more than the placebo $(t(36)=2.38, p=$ $0.023)$ or quetiapine group $(t(36)=2.75, p=0.009)$ in the post-drug phase.

\section{Discussion}

As has been shown in human studies assessing the impact of SGAs on cognitive performance in pediatric populations (Aman et al. 2008; Gunther et al. 2006; Pandina et al. 2009), neither risperidone nor quetiapine had a negative impact on cognitive development while the animal was taking the drug. However, it was clear in this study that removing risperidone resulted in performance deficits on learning set a month after drug cessation, which has not been assessed in the human literature. This deficit was not due to a lack of attention on the task or to increases in impulsive responding. Attention on trial 1 is often indexed via reaction time. A longer reaction time on trial 1 than trials 2 through 6 suggests that the animal encoded both stimuli before making a choice. The risperidone group maintained this reaction time pattern in the post-drug phase, suggesting that their performance deficit was not due to a lapse in attention. In animals, impulsive responding can be shown by faster reaction times. In addition to maintaining 
the adaptive reaction time pattern, the risperidone group did not have faster reaction times than the other two groups, indicating that the change in reaction time across the study was due to developmental changes in global processing speed, not to impulsive responding. Given that animals in all three groups were also able to maintain their two-object discrimination performance at a high level, the deficit seen in the risperidone animals was not due to a failure to discriminate either. Rather the performance deficit in the post-drug phase likely reflects either response inflexibility or an inability to adjust behavior based on feedback, both of these explanations are supported by the animals' perseverative behavior on trial 2. Both of these behavioral explanations suggest an underlying DA disturbance (Cools et al. 2009; Tremblay et al. 1998).

While a serotonergic disturbance cannot be ruled out, it is unlikely. Both quetiapine and risperidone impact the serotonergic system (Tarazi et al. 2002). However, the quetiapine group did not show a post-drug behavioral disturbance. It is more likely that the decrement in postdrug performance by the risperidone group was due to an effect on the DA system. Quetiapine does not significantly affect D2 or D4 receptors in vitro (Schotte et al. 1996), and the animals receiving quetiapine in this study did not show signs of D2 antagonism as indexed by elevated prolactin levels (Roke et al. 2009).

Another alternative explanation for these results could be a disturbance between temporal and frontal functioning. Disconnecting the fiber tracks between the inferior temporal and frontal areas has been shown to result in deficits on learning set performance (Browning et al. 2007). However, the error types produced by this type of lesion are different from the ones observed in this study. Disconnection of this tract produces errors indicative of a general loss in strategy utilization, whereas in this study, errors were indicative of behavioral inflexibility. Behavioral inflexibility has been shown to rely on DA functioning within the thalamicstriatal-frontal loop (Cools et al. 2009).

While a DA disturbance is likely at the heart of this behavioral effect, it is unclear where this change is occurring. Based on the behavioral effects, it is likely that this problem arises from a DA disturbance in the striatum. Supersensitivity of D2 receptors in the striatum has been documented with chronic administration of antipsychotic drugs. This supersensitivity is often expressed post-drug and results in psychomotor adverse effects. Supersensitivity of D2 receptors is mainly associated with firstgeneration antipsychotic drugs (Samaha et al. 2007; Seeman et al. 2005), but there is documentation of these effects with SGAs (Margolese et al. 2002). However, there was no behavioral or endocrine evidence for supersensitivity in these animals. There was little prolactin adjustment during the moderate-dose phase in the risperidone group. Additionally, there was no evidence for reaction time modulation due to the drug being discontinued, making it unlikely that supersensitivity could be the sole explanation for the behavioral decrements.

Developmental disturbance of the striatial DA system can have a cascading effect that is expressed in other areas. It has been shown that chronic developmental overexpression of $\mathrm{D} 2$ in the striatum results in abnormal frontal DA functioning with regards to neurotransmitter turnover, concentration, and D1 receptor density. This abnormal frontal functioning has been shown to be related to specific deficits in working memory and behavioral flexibility, but not to general cognitive problems (Kellendonk et al. 2006). One of the few studies to assess the impact of risperidone on developmental changes in dopamine receptors found that chronic administration of risperidone in juvenile rats, at a dose level comparable to the one used here, resulted in increased D2 and D4 concentrations in the hippocampus and medial prefrontal cortex among other changes (Moran-Gates et al. 2007). Combining these existing studies with our behavioral findings leads to the hypothesis that antagonism of D2 receptors by risperidone either negatively affected the developmental downregulation of dopamine receptors in the striatum or promoted the developmental overexpression of receptors in the frontal cortex, but this hypothesis should be tested with more research directly measuring this system.

While these data show a clear effect of risperidone on post-drug performance for these young animals, many questions remain. One question concerns whether the effect endures over a longer post-drug period. There are no studies that have assessed whether receptor concentration changes after SGA drug administration are enduring in juveniles. In adults, it is reasonable to conclude that the effects are transient because symptoms return after drug cessation. With children, it also appears that behavioral symptoms return after cessation of the drugs, but given that the drugs are interacting with a developmental process itself implicated in the behavioral disturbance being treated, it is an open question as to whether these cognitive and hypothesized neural changes are enduring.

Another main question that arises from this study is whether these effects would be present in females. The DA system has different developmental trajectories for males and females (Andersen and Teicher 2000) because of a complex interaction involving the sensitization effects of sex steroids on DA receptors (Andersen et al. 1997; Anderson et al. 2005). There have been sex differences reported in plasma concentrations of SGAs and severity of adverse effects (Aichhorn et al. 2007). Therefore, it is likely that the degree to which risperidone and other D2 antagonists affect cognitive development may be different 
for females and males. Given the findings of this study, post-drug effects of administering SGAs in young children should be studied and characterized.

Acknowledgments This study was supported by NIH grants MH064647 to G. Sackett, RR00166 to the Washington National Primate Research Center, and HD02774 to the University of Washington Center on Human Development and Disability. We thank Brenda Crouthamel, Sarah Ward, Rebecca Warren, Erika Rainwater, and Caroline Kenney for data collection. Neither DJM nor GPS have conflicts of interest. Unis was employed from 2001-2003 by Johnson \& Johnson Pharmaceutical Research and Development, LLC and worked on the pediatric exclusivity research related to the development of risperidone. However, the primate study for this publication was developed before his employment and the data collection was completed after his employment ended. Unis is a speaker for Jannsen Pharmaceuticals, Inc. but risperidone is no longer promoted by this company since its patent expired.

Open Access This article is distributed under the terms of the Creative Commons Attribution Noncommercial License which permits any noncommercial use, distribution, and reproduction in any medium, provided the original author(s) and source are credited.

\section{References}

Aichhorn W, Marksteiner J, Walch T, Zernig G, Hinterhuber H, Stuppaeck C, Kemmler G (2007) Age and gender effects on olanzapine and risperidone plasma concentrations in children and adolescents. J Child Adolesc Psychopharmacol 17:665674

Aman MG, Hollway JA, McDougle CJ, Scahill L, Tierney E, McCracken JT, Arnold LE, Vitiello B, Ritz L, Gavaletz A, Cronin P, Swiezy N, Wheeler C, Koenig K, Ghuman JK, Pose DJ (2008) Cognitive effects of risperidone in children with autism and irritable behavior. J Child Adolesc Psychopharmacol 18:227-236

Andersen SL, Teicher MH (2000) Sex differences in dopamine receptors and their relevance to ADHD. Neurosci Biobehav Rev 24:137-141

Andersen SL, Rutstein M, Benzo JM, Hostetter JC, Teicher MH (1997) Sex differences in dopamine receptor overproduction and elimination. NeuroReport 8:1495-1498

Anderson LI, Leipheimer RE, Dluzen DE (2005) Effects of neonatal and prepubertal hormonal manipulations upon estrogen neuroprotection of the nigrostriatal dopaminergic system within female and male mice. Neuroscience 130:369-382

Bishop JR, Pavuluri MN (2008) Review of risperidone for the treatment of pediatric and adolescent bipolar disorder and schizophrenia. Neuropsychiatr Dis Treat 4:55-68

Browning PGF, Easton A, Gaffan D (2007) Frontal-temporal disconnection abolishes object discrimination learning set in macaque monkeys. Cereb Cortex 17:859-864

Chang KD (2008) The use of atypical antipsychotics in pediatric bipolar disorder. J Clin Psychiatry 69:4-8

Cools R (2006) Dopaminergic modulation of cognitive functionimplications for L-DOPA treatment in Parkinson's disease. Neurosci Biobehav Rev 30:1-23

Cools R, Frank MJ, Gibbs SE, Miyakawa A, Jagust W, D’Esposito M (2009) Striatal dopamine predicts outcome-specific reversal learning and its sensitivity to dopaminergic drug administration. J Neurosci 29:1538-1543

Gunther T, Herpertz-Dahlmann B, Jolles J, Konrad K (2006) The influence of risperidone on attentional functions in children and adolescents with attention-deficit/hyperactivity disorder and co-morbid disruptive behavior disorder. J Child Adolesc Psychopharmacol 16:725-735

Harlow HF (1949) The formation of learning sets. Psychol Rev $56: 51-65$

Harlow HF, Harlow MK, Rueping RR, Mason WA (1960) Performance of infant rhesus monkeys on discrimination learning, delayed response, and discrimination learning set. J Comp Physiol Psychol 53:113-121

Haycock JW, Becker L, Ang L, Furukawa Y, Hornykiewicz O, Kish SJ (2003) Marked disparity between age-related changes in dopamine and other presynaptic dopaminergic markers in human striatum. J Neurochem 87:574-585

Kellendonk C, Simpson EH, Polan HJ, Malleret G, Vronskaya S, Winiger V, Moore H, Kandel ER (2006) Transient and selective overexpression of dopamine D2 receptors in the striatum causes persistent abnormalities in prefrontal cortex functioning. Neuron 49:603-615

Kowatch RA, Fristad M, Birmaher B, Wagner KD, Findling RL, Hellander M (2005) Treatment guidelines for children and adolescents with bipolar disorder. J Am Acad Child Adolesc Psychiatry 44:213-235

Kuroki T, Meltzer HY, Ichikawa J (1999) Effects of antipsychotic drugs on extracellular dopamine levels in rat medial prefrontal cortex and nucleus accumbens. J Pharmacol Exp Ther 288:774 781

Lambe EK, Krimer LS, Goldman-Rakic PS (2000) Differential postnatal development of catecholamine and serotonin inputs to identified neurons in prefrontal cortex of rhesus monkey. J Neurosci 20:8780-8787

Levinson B, Reese HW (1967) Patterns of discrimination learning set in preschool children, fifth-graders, college freshmen, and the aged. Monogr Soc Res Child Dev 32:1-92

Mandell DJ, Sackett GP (2009) Comparability of developmental cognitive assessments between standard and computer testing methods. Dev Psychobio 51:1-13

Margolese HC, Chouinard G, Beauclair L, Belanger MC (2002) Therapeutic tolerance and rebound psychosis during quetiapine maintenance monotherapy in patients with schizophrenia and schizoaffective disorder. J Clin Psychopharmacol 22:347352

Meltzer HY, McGurk SR (1999) The effects of clozapine, risperidone, and olanzapine on cognitive function in schizophrenia. Schizophr Bull 25:233-255

Moran-Gates T, Grady C, Park YS, Baldessarini RJ, Tarazi FI (2007) Effects of risperidone on dopamine receptor subtypes in developing rat brain. Eur Neuropsychopharmacol 17:448455

Pandina GJ, Bilder R, Harvey PD, Keefe RSE, Aman MG, Gharabawi G (2007) Risperidone and cognitive function in children with disruptive behavior disorders. Biol Psychiatry 62:226-234

Pandina GJ, Zhu Y, Cornblatt B (2009) Cognitive function with longterm risperidone in children and adolescents with disruptive disorder. J Child Adolesc Psychopharmacol 19:749-756

Reese HW (1989) Discrimination learning set in children. Adv Child Dev Behav 21:153-189

Roke Y, van Harten PN, Boot AM, Buitelaar JK (2009) Antipsychotic medication in children and adolescents: a descriptive review of the effects on prolactin level and associated side effects. J Child Adolesc Psychopharmacol 19:403-414

Sackett GP, Unis A, Crouthamel B (2010) Some effects of risperidone and quetiapine on growth parameters and hormone levels in young pigtail macaques. J Child Adolesc Psychopharmacol (in press)

Samaha AN, Seeman P, Stewart J, Rajabi H, Kapur S (2007) "Breakthrough" dopamine supersensitivity during ongoing anti- 
psychotic treatment leads to treatment failure over time. J Neurosci 27:2979-2986

Schotte A, Janssen PFM, Gommeren W, Luyten W, VanGompel P, Lesage AS, DeLoore K, Leysen JE (1996) Risperidone compared with new and reference antipsychotic drugs: in vitro and in vivo receptor binding. Psychopharmacology 124:57-73

Schultz W (2002) Getting formal with dopamine and reward. Neuron $36: 241-263$

Seeman P, Weinshenker D, Quirion R, Srivastava IAK, Bhardwaj SK, Grandy DK, Premont RT, Sotnikova TD, Boksa P, El-Ghundi M, O'Dowd BF, George SR, Perreault ML, Mannisto PT, Robinson S, Palmiter RD, Tallerico T (2005) Dopamine supersensitivity correlates with D2(high) states, implying many paths to psychosis. Proc Natl Acad Sci USA 102:3513-3518
Tarazi FI, Baldessarini RJ (2000) Comparative postnatal development of dopamine $\mathrm{D}(1), \mathrm{D}(2)$ and $\mathrm{D}(4)$ receptors in rat forebrain. Int $\mathrm{J}$ Dev Neurosci 18:29-37

Tarazi FI, Zhang KH, Baldessarini RJ (2002) Long-term effects of olanzapine, risperidone, and quetiapine on serotonin 1A, 2A and $2 \mathrm{C}$ receptors in rat forebrain regions. Psychopharmacology 161:263-270

Tremblay L, Hollerman JR, Schultz W (1998) Modifications of reward expectation-related neuronal activity during learning in primate striatum. J Neurophysiol 80:964-977

Wahlstrom D, Collins P, White T, Luciana M (2009) Developmental changes in dopamine neurotransmission in adolescence: behavioral implications and issues in assessment. Brain Cogn 72:146159 